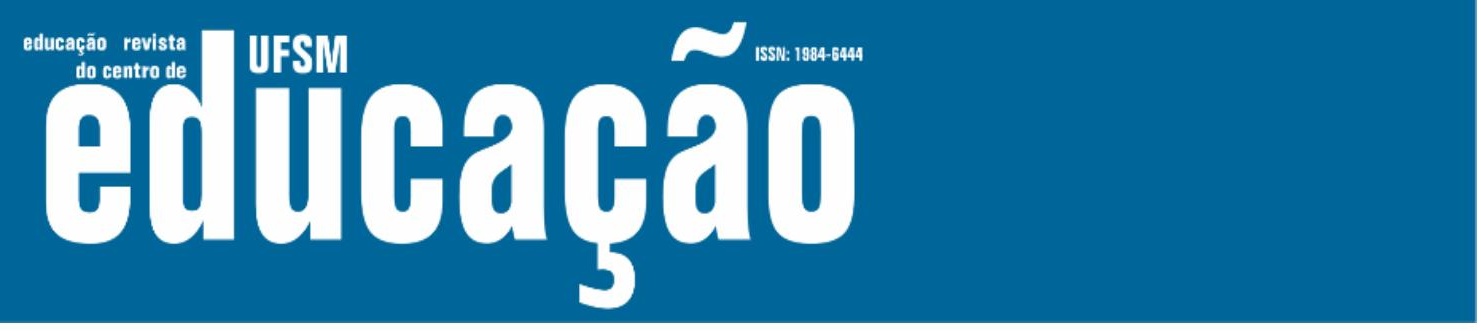

ISSN: 1984-6444 | http://dx.doi.org/10.5902/1984644441231

\title{
A Convenção Sobre os Direitos da Criança e o Direito à Educação no Brasil
}

The Convention on the rights of the Child and the Right to Education in Brazil

\section{La Convención Sobre Los Derechos del Niño y el derecho a la educación en Brasil}

\section{Celeida Maria Costa de Souza e Silva}

Professora doutora na Universidade Católica Dom Bosco, Campo Grande, Mato Grosso do Sul, Brasil. celeidams@uol.com.br - https://orcid.org/0000-0001-7074-5137

Ariadne Celinne de Souza e Silva

Mestranda na Universidade Federal de Mato Grosso do Sul, Campo Grande, Mato Grosso do Sul, Brasil.

ariadnecelinne@uol.com.br - https://orcid.org/0000-0001-5670-2923

Recebido em 20 de novembro de 2019

Aprovado em 06 de setembro de 2020

Publicado em 10 de março de 2021

\section{RESUMO}

Este trabalho tem por objetivo discutir a Convenção Sobre os Direitos da Criança com foco no direito à educação. Estuda-se este direito a partir da perspectiva da criança como sujeito de direitos no direito internacional e nacional e da interpretação dada pelo Comitê Sobre os Direitos da Criança ao direito à educação (artigo 29). É uma pesquisa bibliográfica e documental. Elege-se como principais fontes: a Convenção Sobre os Direitos da Criança, o Comentário Geral o 1 (2001) do Comitê Sobre os Direitos da Criança, os relatórios periódicos enviados pelo Brasil $(2003,2012)$ ao Comitê, a Constituição da República Federativa do Brasil de 1988 e o Estatuto da Criança e do Adolescente. Percebe-se que há uma preocupação com a educação da Criança perante os tratados internacionais de direitos humanos, a legislação nacional, e, também, por meio de agendas de desenvolvimento que pautam a educação como centro para a efetivação dos demais direitos.

Palavras-chave: Convenção Sobre os Direitos da Criança; Educação; Direitos Humanos. 


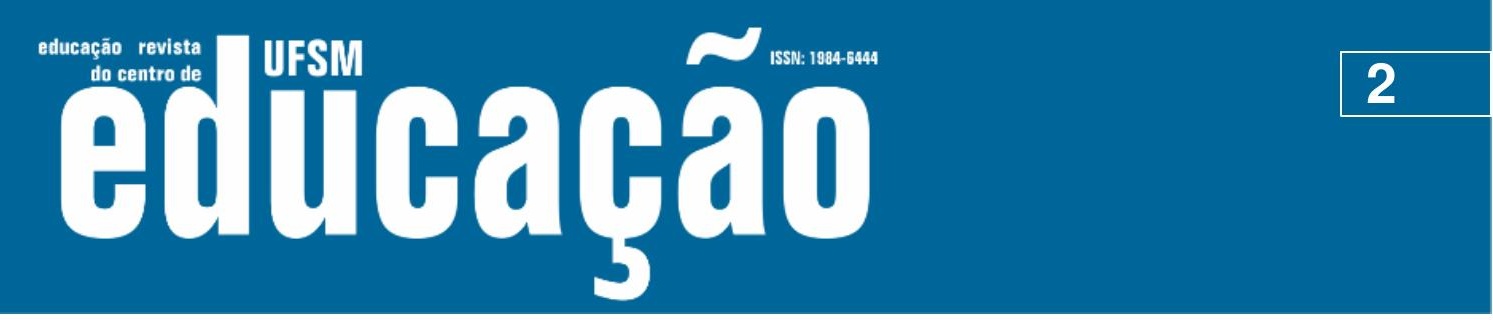

ISSN: 1984-6444 | http://dx.doi.org/10.5902/1984644441231

\section{ABSTRACT}

This paper has as its aim the analysis of the Convention on the rights of the child focusing on the right to education. We study this right from the perspective of the child as subjective of rights in the international and national law and of the interpretation of the right to education (article 29) given by the Committee on the Rights of the Child). It is a bibliographic and documental research. We elect as main source: The Convention of The rights of the Child, the General Comment no 1 (2001) of the Committee on the Rights of the Child, the periodic reports sent by Brazil $(2003,2012)$ to the Committee, the Constitution of the Federative Republic of Brazil and the Child and Adolescent Statute. We realize that is a concern with the child's education in front of international human rights treaties, the national legislation and by development agendas that are guided by education as a core for the realization of the other rights.

Keywords: The Convention of the rights of the child; education; human rights.

\section{RESUMEN}

Este trabajo tiene como propósito discutir la Convención Sobre Los Derechos Del Niño con enfoque en el derecho a la educación. Se estudia este derecho a partir de la perspectiva del niño como sujeto de derechos en derecho internacional y nacional y de la interpretación dada por el Comité de los derechos del Niño al derecho a la educación (artículo 29). Esta es una investigación bibliográfica y documental. Se escoge como fuentes esenciales: La Convención Sobre Los Derechos del Niño, la observación general número 1 (2001) del Comité de los Derechos del Niño, los informes periódicos enviados por Brasil $(2003,2012)$ al comité, la Constitución de la República Federativa de Brasil de 1988 y el Estatuto del Niño y del Adolescente. Se observa que hay una preocupación con la educación del Niño en los tratados de derechos humanos, en la legislación nacional y también en las agendas de desarrollo que se guían por la educación como foco para la realización de los derechos.

Palabras Clave: La Convención Sobre Los Derechos Del Niño; Educación; Derechos Humanos.

\section{Introdução}

O conceito de infância como uma etapa da vida de uma pessoa surgiu a partir do século XVII com o início da vida escolar, antes desse momento a criança não recebia qualquer tratamento especial, nem vínculos ou obrigações do Estado e de seus pais quanto ao seu bem-estar: 


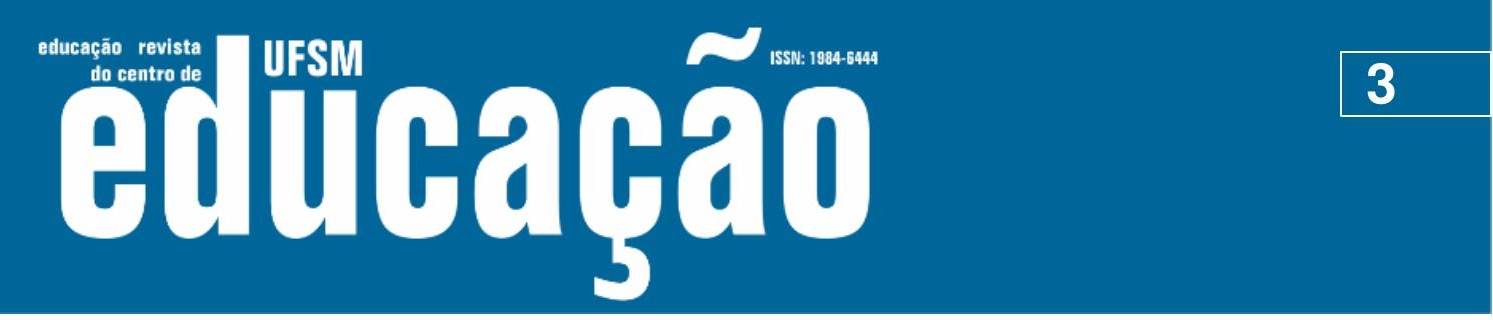

ISSN: 1984-6444 | http://dx.doi.org/10.5902/1984644441231

O sentimento de desconsideração para com a criança perdurou por toda a Idade Média e início dos tempos modernos, apenas sendo modificado parcialmente no século XVII. $O$ dispêndio parental durava até aproximadamente os sete anos de idade, sendo que após essa idade a criança se misturava aos adultos, sendo obrigada a atuar e agir conforme estes, sem uma identidade, sem um tratamento especial. Não possuíam privacidade ou intimidade, a sua vida era agregada às demais, sem um cômodo próprio, sem roupas específicas, às vezes até sem uma família própria, andavam pelas ruas sozinhas, submetidas às mesmas duras leis destinadas a qualquer cidadão livre (VERONESE, 2013, p.42)

Entretanto, as escolas dos séculos XVIII e XIX tinham como principal característica a rigidez, e apenas no final do século XIX e início do século XX passouse a respeitar às crianças, educando-as para o futuro da sociedade (VERONESE, 2013, p.43).

O processo de reconhecimento da criança como sujeito de direitos ${ }^{1}$ no âmbito internacional acompanhou a evolução do Direito Internacional de Direitos Humanos, e o próprio conceito de indivíduo como sujeito de direitos. De início foram estabelecidos apenas princípios guias, sem um vínculo ou uma obrigação dos Estados signatários para com os direitos das crianças, até que a partir da Convenção dos Direitos da Criança de 1989, originou-se um verdadeiro microssistema de direitos humanos das crianças.

\section{A Construção do Direito da Criança}

Em 1924, a Declaração de Genebra ou Declaração Sobre os Direitos da Criança foi adotada na quinta Assembleia da Liga das Nações. Entretanto esta declaração não estipulava obrigações para os Estados, somente para "homens e mulheres de todas as nações" que reconheciam o dever da humanidade em fornecer meios para que as crianças se desenvolvessem tanto material, quanto espiritualmente. Nesta declaração são citados princípios que fundamentam os direitos da criança: 


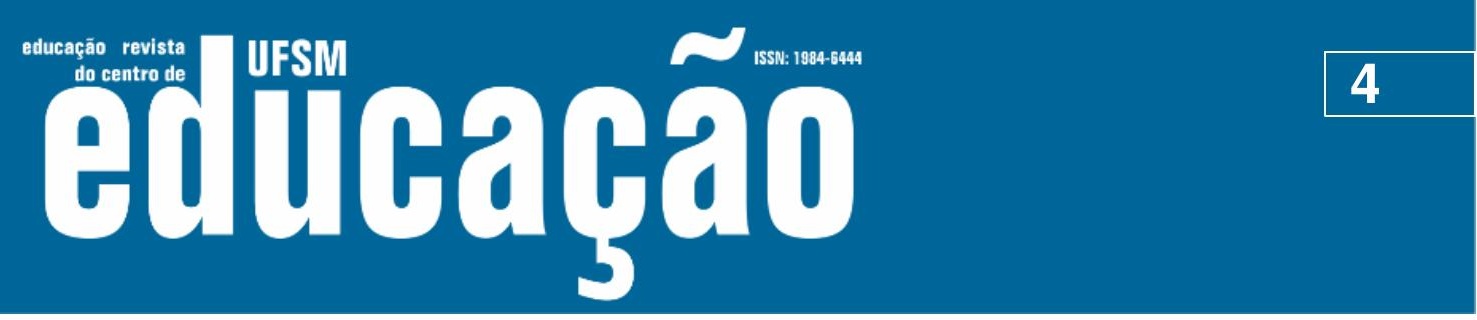

ISSN: 1984-6444 | http://dx.doi.org/10.5902/1984644441231

Pela presente Declaração dos Direitos da Criança, comumente conhecida como Declaração de Genebra, homens e mulheres de todas as nações, reconhecendo que a humanidade deve às crianças o melhor do que há para ser dado, declaram e aceitam como sua responsabilidade que, além e acima de qualquer consideração de raça, nacionalidade e credo:

I. Às Crianças devem ser concedidos os meios necessários para o seu desenvolvimento, tanto material quanto espiritual;

II. A criança que tem fome, tem de ser alimentada; a criança que está doente, deve ser socorrida; a criança que está atrasada deve ser ajudada; a criança delinquente deve ser recuperada; e a órfã e a abandonada deve ser protegida e socorrida;

III. A criança deve ser a primeira a receber ajuda em tempos de sofrimento; IV. A criança deverá ser capaz de se sustentar e deve ser protegida de todas as formas de exploração;

V. A criança deve ser educada com a consciência de que seus talentos devem ser dedicados a seus semelhantes.

(LIGA DAS NAÇÕES, Declaração dos Direitos da Criança, 1924, livremente traduzida para este trabalho²)

A partir da assinatura da Carta das Nações Unidas em 1945, os países signatários passaram a firmar compromissos com as próximas gerações para que a justiça e o respeito às obrigações dos tratados fossem mantidos a fim de que a humanidade alcançasse um progresso social e melhores condições de vida. ${ }^{3}$

Tais compromissos foram reafirmados em 1948, por meio da proclamação da Declaração Universal dos Direitos Humanos (DUDH), a qual reconheceu valores de dignidade, liberdade e um rol de direitos para todos os humanos sem distinção.

Em 1959, foi proclamada pela Assembleia das Nações Unidas a Declaração dos Direitos da Criança ${ }^{4}$, reforçando os valores estabelecidos na DUDH e proclamando dez princípios visando a uma infância feliz. Esta declaração determina que a criança deve ser protegida para que possa alcançar seu desenvolvimento completo e harmonioso, pois é imatura física e mentalmente, precisando de proteção e cuidados especiais.

Nota-se uma evolução desse texto em comparação à Declaração de 1924, mas a definição de criança e a criação de mecanismos que vinculassem os Estados Partes perante as crianças viria por meio de tratados nucleares do Direito Internacional: O Pacto Internacional de Direitos Civis e Políticos de 1966, o Pacto Internacional de Direitos Econômicos Sociais e Culturais de $1966^{5}$, a Convenção no 138 da Organização Internacional do Trabalho de 1973 e a Convenção Sobre os Direitos da Criança de 1989. 


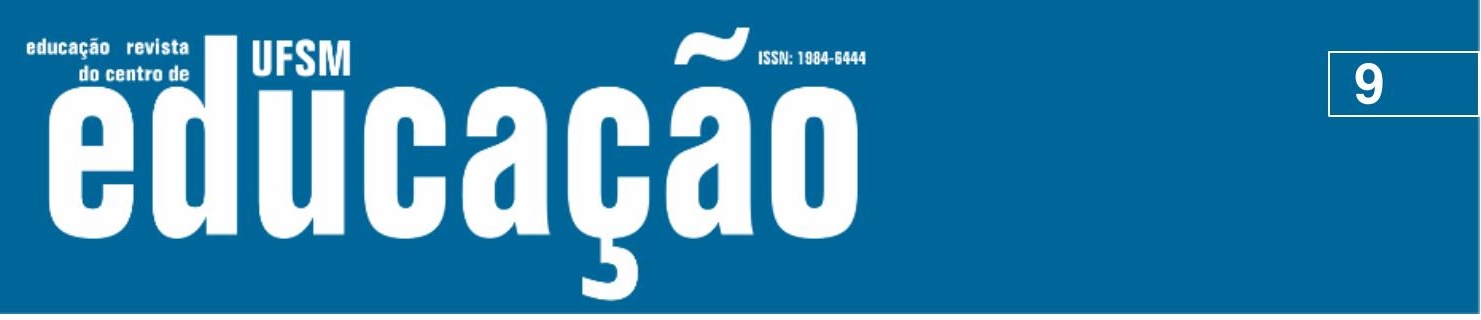

ISSN: 1984-6444 | http://dx.doi.org/10.5902/1984644441231

O Brasil ratificou a Convenção e seus Protocolos, entretanto, o Protocolo relativo aos procedimentos de comunicação ainda não foi incorporado ao direito interno, pois não houve decreto presidencial de promulgação ${ }^{17}$. Esse protocolo é de fundamental importância, pois possibilita que as crianças, até mesmo por meio de petições individuais, apresentem denúncias relativas à violação de seus direitos previstos tanto por meio da Convenção Sobre os Direitos da Criança, quanto de seus protocolos.

Além disso, as comunicações poderão ser apresentadas por indivíduos ou grupo de indivíduos, além de poderem ser apresentadas em nome de indivíduos ou grupo de indivíduos, mediante consentimento. Para isso, o Estado deverá ser parte do instrumento, o qual a comunicação alega ter sido violado.

Essas comunicações serão avaliadas pelo Comitê para os Direitos da Criança $^{18}$, o qual tem competência para monitorar a efetivação da Convenção sobre o Direito da Criança e dos respectivos protocolos facultativos e, por isso, também deve analisar os relatórios que os Estados Partes são obrigados a enviar periodicamente.

Como visto, a construção do direito à criança deu-se de maneira interdisciplinar e progressiva no âmbito internacional. Como o exercício do direito à Educação é fundamental para a formação da criança como indivíduo e permeia a efetivação dos demais direitos previstos na Convenção sobre os Direitos da Criança, optamos por trabalhar este direito a partir do estabelecido nesta Convenção.

Inclusive, a interpretação dos propósitos da Educação trabalhados pelo Comitê em seu Comentário Geral no $1^{19}$ à Convenção sobre os Direitos da Criança é de que o Artigo $29^{20}$ da Convenção objetiva o desenvolvimento do potencial completo da criança por meio da educação em direitos humanos, do desenvolvimento de um senso de identidade, além da filiação, socialização e interação da criança com outros e com o meio ambiente.

Além disso, o Comitê ressalta que, por meio do artigo 29, pode-se notar que os direitos estabelecidos na Convenção Sobre os Direitos da Criança são interligados, podendo este fenômeno ser exemplificado pelos direitos: a não discriminação (artigo $\left.2^{\circ}\right)$; ao melhor interesse da criança (artigo $3^{\circ}$ ); à vida, sobrevivência e desenvolvimento (Art. 6으); a se expressar e ser levado em consideração (artigo 12); 


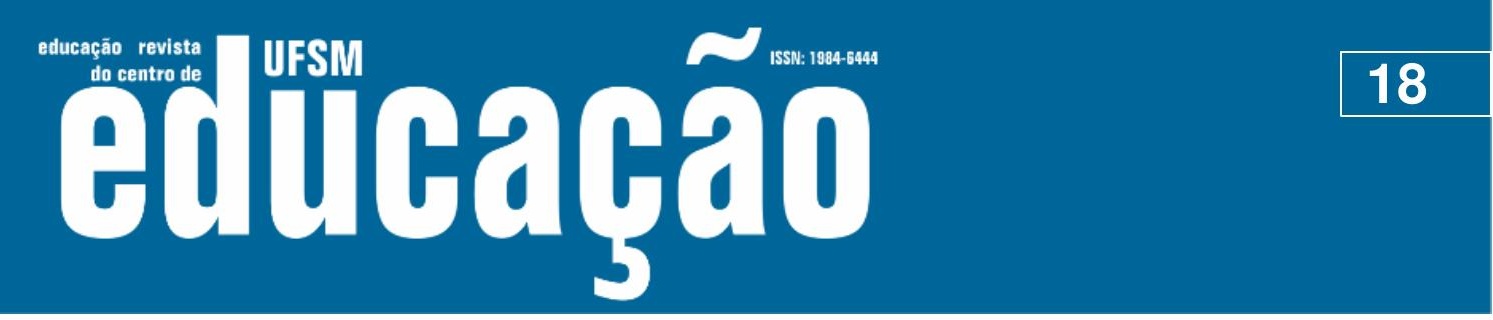

ISSN: 1984-6444 | http://dx.doi.org/10.5902/1984644441231

BRASIL. Committee on the rights of the child: Consideration of reports submitted under article 44 of the convention. CRC/C/3/Add.66. Outubro de 2003. Disponível em: https://tbinternet.ohchr.org/_layouts/15/treatybodyexternal/Download.aspx?symbolno $=\mathrm{CRC} \% 2 \mathrm{fC} \% 2 \mathrm{f} 3 \% 2 \mathrm{fAdd} .65$ \&Lang=en Acesso em 11 de novembro de 2019.

BRASIL. Comittee on the rights of child: Consideration of reports submitted by States parties under article 44 of the Convention. CRC/C/BRA/2-4. Dezembro de 2012. Disponível

em: https://tbinternet.ohchr.org/_layouts/15/treatybodyexternal/Download.aspx?symbolno $=\mathrm{CRC} \% 2 \mathrm{fC} \% 2 \mathrm{fBRA} \% 2 \mathrm{f} 2-4 \& \mathrm{~L}$ ang=en Acesso em 11 de novembro de 2019.

BRASIL. Constituição da República Federativa do Brasil de 1988. Disponível em: http://www.planalto.gov.br/ccivil_03/constituicao/ConstituicaoCompilado.htm

BRASIL. Decreto no 99.710, de 21 de novembro de 1990. Disponível em: http://www.planalto.gov.br/ccivil_03/decreto/1990-1994/D99710.htm

BRASIL. Decreto no 591, de 6 de julho de 1992. Disponível em: http://www.planalto.gov.br/ccivil_03/decreto/1990-1994/d0591.htm

BRASIL. Decreto no 592, de 6 de julho de 1992. Disponível em: http://www.planalto.gov.br/ccivil_03/decreto/1990-1994/d0592.htm

BRASIL. Decreto no 4.134, de 15 de fevereiro de 2002. Disponível em: http://www.planalto.gov.br/ccivil_03/decreto/2002/D4134.htm

BRASIL. Decreto no 5.006, de 8 de março de 2004. Disponível em: http://www.planalto.gov.br/ccivil_03/_Ato2004-2006/2004/Decreto/D5006.htm

BRASIL. Decreto no 5.007, de 8 de março de 2004. Disponível em: http://www.planalto.gov.br/ccivil_03/_Ato2004-2006/2004/Decreto/D5007.htm

BRASIL. Decreto no 5.452, de 1으 de maio de 1943. Disponível em: http://www.planalto.gov.br/ccivil_03/decreto-lei/Del5452compilado.htm

BRASIL. Decreto Legislativo no 85 de 2017. Disponível em: https://www2.camara.leg.br/legin/fed/decleg/2017/decretolegislativo-85-8-junho2017-785032-protocolo-152998-pl.html

BRASIL. Lei no 8069, de 13 de julho de 1990. Disponível em: http://www.planalto.gov.br/ccivil_03/leis//8069.htm

BRASIL. Lei no 9.394, de 20 de dezembro de 1996. Disponível em: http://www.planalto.gov.br/ccivil_03/leis/19394.htm

BRASIL. Lei no 13.005, de 25 de junho de 2014. Disponível em: http://www.planalto.gov.br/ccivil_03/_Ato2011-2014/2014/Lei/L13005.htm 


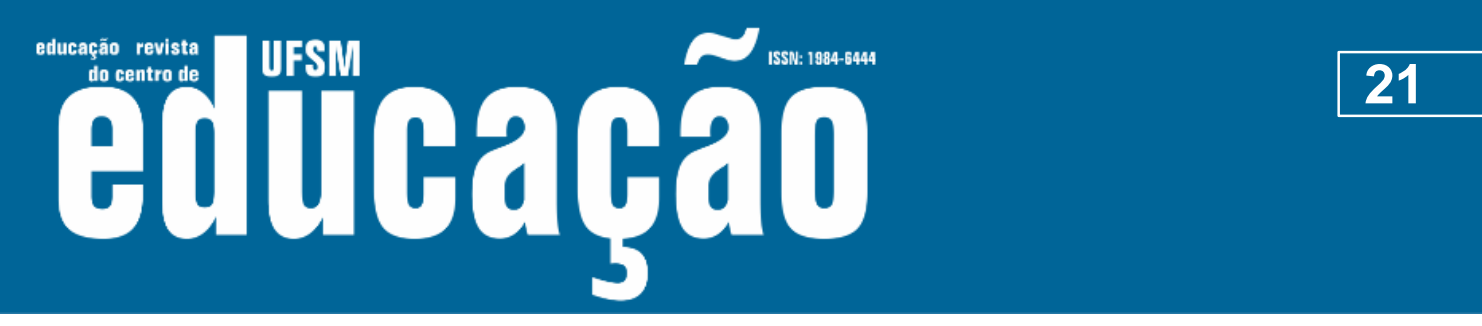

ISSN: 1984-6444 | http://dx.doi.org/10.5902/1984644441231

VERONESE, Josiane Rose Petry. Os direitos da Criança e do Adolescente: Construindo o Conceito de Sujeito-Cidadão. IN: WOLKMER, Antonio Carlos e LEITE, José Rubens Morato. (org). Os “novos” direitos no Brasil: natureza e perspectivas - Uma visão básica das novas conflituosidades jurídicas. 2. Ed. São Paulo: Saraiva, 2012. P. 49-69

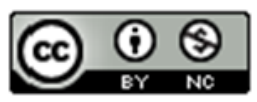

This work is licensed under a Creative Commons Attribution-NonCommercial 4.0 International (CC BY-NC 4.0)

\title{
Notas
}

\begin{abstract}
${ }^{1}$ PORTELA (2012, p.169) define como sujeitos de direito internacional em um entendimento moderno àqueles que passaram a ter direitos e obrigações estabelecidos pelas normas internacionais.

${ }^{2}$ Para acessar o texto original consultar: United Nations. Legislative History of the Convention on the Rights of The Child. Volume I: New York and Geneva, 2007. p.3

${ }^{3}$ Nações Unidas, Carta das Nações Unidas, 1945, Preâmbulo.

${ }^{4}$ Declaração dos Direitos da Criança foi proclamada pela Assembleia Geral em 20 de novembro de 1959 pela resolução 1386 (XIV). Op. Cit. United Nations. Legislative History of the Convention on the Rights of The Child. Volume I: New York and Geneva, 2007. p.23-25.

${ }^{5}$ O Pacto Internacional sobre Direitos Civis e Políticos foi promulgado pelo Decreto $\mathrm{n}^{\mathrm{o}} 592$, de 06 de julho de 1992, enquanto o Pacto Internacional sobre Direitos Econômicos, Sociais e Culturais foi promulgado pelo Decreto $\mathrm{n}^{\circ}$ 591, de 06 de julho de 1992

${ }^{6}$ A Convenção $n^{\circ} 138$ da Organização Internacional do Trabalho (OIT), Convenção Sobre a Idade Mínima, foi adotada em 26 de junho de 1973 pela Conferência Geral da Organização Internacional do Trabalho. Foi ratificada pelo Brasil em 28 de junho de 2001 e promulgada pelo Decreto $n^{\circ} 4.134$, de 15 de fevereiro de 2002.
\end{abstract}

${ }^{7}$ Op. Cit. Artigos $2^{\circ}, 3^{\circ}, 4^{\circ}$ da Convenção 138 da OIT de 1973.

${ }^{8}$ Op. Cit. Artigos $7^{\circ}, 8^{\circ}$ da Convenção 138 da OIT de 1973.

${ }^{9}$ Op. Cit. Artigos $3^{\circ}, 5^{\circ}, 7^{\circ}$ da Convenção 138 da OIT de 1973.

${ }^{10}$ A proteção do trabalho do menor está prevista no Art. $7^{\circ}$, XXXIII da Constituição da República Federativa do Brasil de 1988 (CRFB/88) e no Decreto-Lei n ${ }^{\circ}$ 5.452, de $1^{\circ}$ de maio de 1943, Consolidação das Leis do Trabalho do artigo 402 ao artigo 410.

${ }^{11}$ Entrou em vigor em âmbito internacional em 02 de setembro de 1990.

${ }^{12}$ Foi adotado pela Assembleia Geral das Nações Unidas em 25 de maio de 2000, entrou em vigor internacional em 12 de fevereiro de 2002. No Brasil, foi promulgado pelo Decreto no 5006, de 8 de março de 2004.

${ }^{13}$ Foi adotado pela Assembleia Geral das Nações Unidas em 25 de maio de 2000. Entrou em vigor internacional em 18 de janeiro de 2002. No Brasil, foi promulgado pelo Decreto $n^{\circ} 5.007$ de 8 de março de 2004.

${ }^{14}$ Foi adotado pela Assembleia Geral das Nações Unidas em 19 de dezembro de 2001. Entrou em vigor internacional em 14 de abril de 2014. Foi Ratificado pelo Brasil em 29 de setembro de 2017, aprovado pelo Decreto 


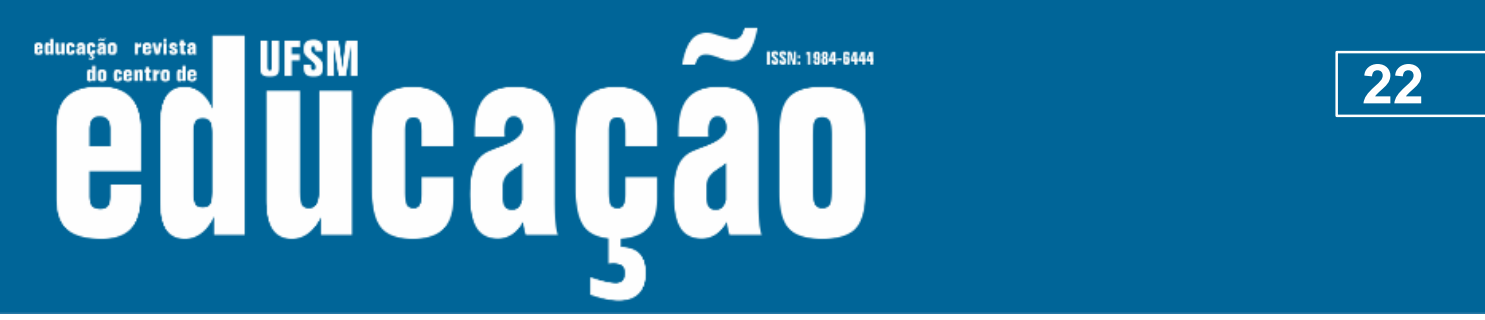

ISSN: 1984-6444 | http://dx.doi.org/10.5902/1984644441231

Legislativo $\mathrm{n}^{\circ} 84$, de 8 de junho de 2017. Até a finalização deste artigo não havia decreto de promulgação presidencial.

${ }^{15}$ Preâmbulo, Convenção sobre os Direitos da Criança,1989, Decreto nº 99.710/1990.

${ }^{16}$ Art. $4^{\circ}$, Convenção sobre os Direitos da Criança,1989, Decreto n ${ }^{\circ}$ 99.710/1990.

${ }^{17}$ André de Carvalho Ramos resume em três fases do Brasil de celebrar um tratado: a fase de assinatura, a fase de aprovação congressual ou decreto legislativo e a fase de ratificação. Ainda há a quarta fase, do decreto presidencial ou decreto de promulgação, em que há a incorporação do tratado já celebrado pelo Brasil ao ordenamento interno. (RAMOS, André de Carvalho. Curso de Direitos Humanos. Parte III, 3.1.3 As quatro fases: da formação da vontade à incorporação)

${ }^{18}$ O Comitê Sobre os Direitos da Criança será tratado a partir deste ponto somente como Comitê.

${ }^{19}$ UNITED NATIONS. Convention on the rights of the child: General Comment no 1. Article 29 (1): The Aims of Education. (2001, p.2).

${ }^{20}$ Ver Artigo 29, Convenção sobre os Direitos da Criança, Decreto nº 99.710/1990.

${ }^{21}$ Op. Cit. Convention on the rights of the child: General Comment no 1. Article 29 (1): The Aims of Education (United Nations, 2001, p.3).

${ }^{22}$ Ver Artigo 28, Convenção sobre os Direitos da Criança, Decreto nº 99.710/1990, grifo nosso)

${ }^{23}$ Op. Cit. Convention on the rights of the child: General Comment no 1. Article 29 (1): The Aims of Education (United Nations, 2001, p.2).

${ }^{24}$ Op. Cit. (United Nations, 2001, p. 4).

${ }^{25}$ Op. Cit. (United Nations, 2001, p. 4).

${ }^{26}$ Op. Cit. (United Nations, 2001, p. 5).

${ }^{27}$ Op. Cit. (United Nations, 2001, p. 5-6).

${ }^{28}$ Op. Cit. (United Nations, 2001, p. 6-7).

${ }^{29}$ Ver Art. $3^{\circ}$, Lei 8069/90.

${ }^{30}$ Ver Art. $4^{\circ}$ Lei 8069/90.

${ }^{31}$ Ver Art. Art. $5^{\circ}, \S 3^{\circ}, \mathrm{CRFB} / 88$.

${ }^{32} \mathrm{O}$ STF em sede do Recurso Extraordinário 466.343 - SP em 03 de dezembro de 2008, em que se discute a prisão civil do depositário infiel, adotou a posição de que os tratados e convenções de direitos humanos possuem caráter supralegal. RE n $\mathrm{n}^{\circ}$ 4666.343-SP, rel. min. Cezar Peluso. DJE de 5-6.2009., Tema 60. Disponível em: http://redir.stf.jus.br/paginadorpub/paginador.jsp?docTP=AC\&docID $=595444$

${ }^{33}$ Art. $227, \S 1^{\circ}, \mathrm{CRFB} / 88$

${ }^{34}$ Ver Art. 227, $\S 3^{\circ}, \mathrm{CRFB} / 88$ )

${ }^{35}$ A educação básica é obrigatória e gratuita dos quatro aos dezessete anos de idade, sendo organizada pela préescola, ensino fundamental e ensino médio conforme o Art. $4^{\circ}$, I, da Lei 9.394/1996.

${ }^{36}$ A Lei 8069/90 dispõe sobre o direito à educação, à cultura, ao esporte e ao lazer do Art. 53 ao Art. 59.

${ }^{37}$ Ver Art. 44, Convenção sobre os Direitos da Criança, Decreto no 99.710/1990.

${ }^{38}$ BRASIL. Committee on the rights of the child: Consideration of reports submitted under article 44 of the convention. CRC/C/3/Add.66. Outubro de 2003.

${ }^{39}$ Este documento é um combinado relativos aos segundos, terceiro e quartos relatório dos Estados Partes que tinha prazo para ser enviado até 2007. BRASIL. Committee on the rights of child: Consideration of reports submitted by States parties under article 44 of the Convention. CRC/C/BRA/2-4. Dezembro de 2012. 


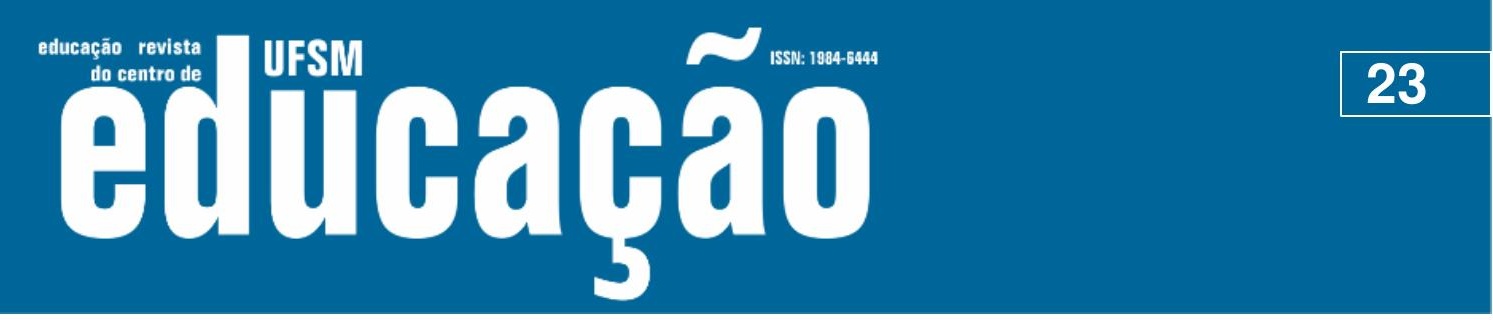

ISSN: 1984-6444 | http://dx.doi.org/10.5902/1984644441231

${ }^{40}$ O CONANDA define as políticas para a área de infância e da adolescente, além de controlar e supervisionar a implementação destas. Para saber mais acessar https://www.direitosdacrianca.gov.br/conanda

${ }^{41}$ Os Conselhos dos Direitos da Criança e do Adolescente foram incorporados à estrutura do Estado pelo ECA, possuem natureza colegiada sendo compostos paritariamente por organizações governamentais e não governamentais, possuem competência para controlar as ações da política de atendimento em todos os níveis. (ASSIS, SG., et al, orgs., Teoria e prática dos conselhos tutelares e conselhos dos direitos da criança e do adolescente. Cap. 2. Conselhos dos direitos da criança e do adolescente, 2009. E-book kindle)

42 Os conselhos tutelares são definidos pelo ECA como órgãos permanentes e autônomos, não jurisdicionais, encarregados pela sociedade de zelar pelo cumprimento dos direitos da criança e do adolescente definidos pelo ECA. Em cada município ou região administrativa haverá no mínimo um conselho tutelar, composto por cinco membros escolhidos pela população local para mandado de 04 anos, permitida a recondução (BRASIL, Art. 131 e Art. 132, Lei 8.069/1990).

${ }^{43}$ Op. Cit. (BRASIL, 2003, p. 10).

${ }^{44}$ Op. Cit. (BRASIL, 2003, p.11).

${ }^{45}$ Op. Cit. (BRASIL, 2003, p.13).

46 "Bearing in mind that the most recent international instruments for human rights stress the indivisibility between civil, political, economic, social and cultural rights, when considering children and adolescents' rights as human rights, they must be guaranteed as a whole, from an integral standpoint. This means that disrespect for any right implies that all the human rights, in one way or another, are violated, since they are interlinked and the guarantee of one right presupposes the guarantee of the others" (BRASIL, 2003, p. 13-14).

${ }^{47}$ Op. Cit. (BRASIL, 2003, p.90).

${ }^{48}$ Op. Cit. (BRASIL, 2003, p.92).

49 Para saber mais https://www.mdh.gov.br/informacao-ao-cidadao/acoes-e-programas/secretaria-nacional-dosdireitos-da-crianca-e-do-adolescente

${ }^{50}$ Op. Cit. (BRASIL, 2012, P.6)

${ }^{51}$ As preocupações e orientações do comitê são extensas e específicas, impossibilitando serem tratadas neste artigo, foi necessário realizar um recorte das recomendações que consideramos pertinentes a este trabalho.

${ }^{52}$ UNITED NATIONS. Committee on the Rights of the Child. Convention on the rights of the child. Concluding observations on the combined second to fourth periodic reports of Brazil. CRC/C/BRA/Co/2-4.Outubro de 2015. P. 18.

53 O próximo documento a ser enviado pelo Brasil tem como prazo estabelecido a data de 23 de abril de 2021.

${ }^{54}$ Os Objetivos de Desenvolvimento Sustentável fazem parte da nova agenda de desenvolvimento sustentável da ONU (Agenda 2030) e é composto por 17 objetivos e suas metas para serem atingidos até 2030. Esta agenda foi lançada em setembro de 2015 durante a Cúpula de Desenvolvimento Sustentável. Saiba mais em: https://nacoesunidas.org/pos2015/

${ }^{55}$ Para acessar as metas ver: https://nacoesunidas.org/pos2015/ods4/

${ }^{56}$ A Declaração de Incheon foi adotada em 21 de maio de 2015 no Fórum Mundial da Educação.

${ }^{57}$ Os objetivos de Desenvolvimento do Milênio (ODM) foram estabelecidos pela ONU em setembro de 2000, durante a Cúpula do Milênio, com objetivos e metas para serem atingidos até 2015. O Objetivo relacionado à educação era o objetivo de número 2: educação básica de qualidade para todos. Saiba mais em: http://www.odmbrasil.gov.br/os-objetivos-de-desenvolvimento-do-milenio

${ }^{58}$ Preâmbulo, Declaração de Incheon. UNESCO. Educação 2030: Declaração de Incheon e Marco de Ação para a implementação do Objetivo de Desenvolvimento Sustentável 4. 2016.

59 INEP. Relatório do $2^{\circ}$ Ciclo de Monitoramento das Metas do Plano Nacional de Educação. Brasília: INEP/MEC:2018. P. 22. 